\title{
Evidence for Suppression of Potassium Conductance by Noradrenaline in Smooth Muscle of Guinea-Pig Vas Deferens
}

\author{
Makoto Wakui and Yasue Fukushi \\ Department of Applied Physiology, Tohoku University \\ School of Medicine, Sendai 980
}

\begin{abstract}
Wakui, M. and Funushi, Y. Evidence for Suppression of Potassium Conductance by Noradrenaline in Smooth Muscle of Guinea-Pig Vas Deferens. Tohoku J. exp. Med., 1986, $150(4), 365-371 —$ The ionic dependency was examined in the reversal potential of the NA-induced membrane depolarization of smooth muscle of the guinea-pig vas deferens, using the double sucrose-gap method. In the control $(5.9 \mathrm{mM} \mathrm{K})$ solution and solutions containing 20 and $60 \mathrm{mM} \mathrm{K}$ ions, replaced with equimolar amount of $\mathrm{Na}$ ions, the reversal potential was negative to the membrane potential at the steady state in each solution, by 19.5, 15.1 and 13.2 $\mathrm{mV}$, respectively. Taking account that the higher external $\mathrm{K}$ concentration causes the larger membrane depolarization, these results indicate that the reversal potential shifted toward the positive direction as the external $\mathrm{K}$ concentration was increased. On the other hand, the calculated equilibrium potential of $\mathrm{K}$ ions in those solutions is $-88,-52$ and $-24 \mathrm{mV}$, respectively. In those solutions, furthermore, the equilibrium potential of $\mathrm{Na}$ ions is 42,38 and $29 \mathrm{mV}$, respectively. However, the equilibrium potentials of $\mathrm{Ca}$ and $\mathrm{Cl}$ ions should be unchanged. Therefore, it is suggested that the reversal potential of the NA-induced depolarization varied in the given different solutions compatibly only with the change in the $\mathrm{K}$ equilibrium potential. This provides evidence that in this tissue, NA induces a reduction in the $\mathrm{K}$ conductance of the cell membrane. - noradrenaline ; depolarization; reversal potential; $\mathrm{K}$ equilibrium potential; guinea-pig vas deferens
\end{abstract}

Though the electrical response of the smooth muscle membrane induced by noradrenaline (NA) varies from tissue to tissue, or even in the same tissue, it varies, depending on the species and the hormonal state as is the case of myometrium, it has been widely accepted that in most of the smooth muscle cells, this substance induces an increase in the ionic conductance of the membrane (Bülbring et al. 1981). For instance, NA induces an increase in the $\mathrm{K}$ conductance of the membrane of the majority of the gastrointestinal tract, resulting in the hyperpolarization (Bülbring and Tomita 1969). In the oestrogen-dominated myometrium of the rat (Marshall 1967) and the guinea-pig (Bülbring and Szurszewski 1974), NA induces an increase in $\mathrm{Na}$ or $\mathrm{Cl}$ conductance resulting in the

Received January 10, 1986; accepted for publication November 5, 1986. 
depolarization. Furthermore in the vascular smooth muscle including the carotid artery (Mekata and Niu 1972) and portal vein (Shuba et al. 1976), the membrane depolarization due to a similar ionic mechanism to that in the myometrium is caused by NA. In the recent years, however, it has been suggested that the depolarization induced by NA in the cases of guinea-pig ureter (Shuba 1977) and rabbit pulmonary artery (Shuba et al. 1976) was associated with a decrease in the membrane conductance. Also in the guinea-pig vas deferens, we observed that the NA-induced depolarization was accompanied by a decrease in the membrane conductance (Wakui and Inomata 1985). In that study, we further found that the reversal potential of the NA-induced depolarization was negative to the resting membrane potential of the smooth muscle cell. This by itself suggested that in the guinea-pig vas deferens, NA induced the membrane depolarization probably by reducing the membrane conductance to $\mathrm{K}$ ions.

In order to confirm the idea, we examined the relationship between the reversal potential of the NA-induced depolarization and the equilibrium potential of $\mathrm{K}$ ions in the guinea-pig vas deferens, by changing the environments with various concentrations of $\mathrm{K}$ ions.

\section{Materials and Methods}

The vasa deferens removed from guinea pigs, 200-250 g, were used. After removing connective tissue surrounding the smooth muscle coat, the vas deferens was opened longitudinally, and a smooth muscle preparation of about $8 \mathrm{~mm}$ in length and $0.6 \mathrm{~mm}$ in diameter was dissected from the longitudinal smooth muscle layer. For measurement of the change in the membrane potential of the smooth muscle cell, the preparation was mounted in a double sucrose-gap chamber which was similar to that described by Anderson (1969). The 'node', the surface of which was perfused with a test solution, was nearly at the center of the preparation in the size of about $0.4 \mathrm{~mm}$. The flow rate of the test solution varied in different experiments ranging from 0.8 to $1.2 \mathrm{ml} / \mathrm{min}$, but it was kept constant in a given series of experiments. The change in the membrane potential in the 'node' was recorded across one sucrose channel of about $4 \mathrm{~mm}$ in width using two $\mathrm{Ag}$ - $\mathrm{AgCl}$ electrodes, one of which was placed near the 'node' and the other, in the outer $\mathrm{KCl}$ channel. In order to give a conditioning polarization, currents were applied to the 'node' across the other sucrose channel. When NA was applied to the preparation, a short application method was used, i.e., the perfusion of the test solution was stopped for a few seconds to inject $0.025 \mathrm{ml}$ of a solution containing NA at the required concentration into the test solution line and then, the perfusion of the test solution was reopened. Since the injection of the NA containing solution was carried out at the point distant from the tissue, the tissue and sucrose-gaps recovered from a transient damage due to the injection before NA reached the tissue. By using this method, the electrical response to NA could be reproduced. The control solution had the following composition (mM) : $\mathrm{NaCl} 117.2, \mathrm{KCl} 5.9, \mathrm{CaCl}_{2} 2.0, \mathrm{MgCl}_{2} 1.2, \mathrm{NaH}_{2} \mathrm{PO}_{4}$ $1.2, \mathrm{NaHCO}_{3} 25.0$, glucose 11.0. For making solutions containing 20 and $60 \mathrm{mM} \mathrm{K}$ ions, the amount of $\mathrm{KCl}$ was increased to each value, replacing with equimolar amount of $\mathrm{NaCl}$. All the solutions were equilibrated with a gas mixture of $95 \% \mathrm{O}_{2}$ and $5 \% \mathrm{CO}_{2}$, and warmed to $37^{\circ} \mathrm{C}$. Guanethidine $\left(10^{-6} \mathrm{M}\right)$ and atropine $\left(10^{-7} \mathrm{M}\right)$ were employed thrcughout all the experiments, in order to avoid possible effects of intrinsic nerve fibres. 


\section{RESULTS}

The reversal potential of the $N A$-induced depolarization in the control solution

As described in a previous paper (Wakui and Inomata 1985), the NA (10-5 M)-induced depolarization of the smooth muscle of guinea-pig vas deferens, which was due to the activation of $\alpha$-adrenergic receptors, was affected by application of electrical conditioning polarization. That is, the conditioning depolarization enhanced while the conditioning hyperpolarization reduced the magnitude of the $\mathrm{NA}$-induced depolarization. In addition, the conditioning hyperpolarization of more than $25 \mathrm{mV}$ in magnitude reversed the NA-induced response to the hyperpolarization. When the magnitude of the NA-induced response was plotted against the membrane potential, taking the resting membrane potential as zero $\mathrm{mV}$, three to four points obtained from the same preparation were roughly on a straight line. Therefore, the membrane potential at which NA could induce no potential change could be decided to be the reversal potential of the NA-induced depolarization. The reversal potential in the control solution ( $5.9 \mathrm{mM} \mathrm{K}$ ) ranged from 24.3 to $17.0 \mathrm{mV}$ (mean \pm s.e. : $19.5 \pm 1.1 \mathrm{mV}, n=7$ ) negative to the resting membrane potential of the smooth muscle cell.

The reversal potentials of the $N A$-induced depolarizations in the 20 and $60 \mathrm{mM} \mathrm{K}$ solutions

In order to observe the effects of external $\mathrm{K}$ ions on the reversal potential of the NA-induced depolarization, the external $\mathrm{K}$ concentration was elevated to 20 mM. As shown in Fig. 1, the potential shifted gradually toward the depolarizing direction by changing the solution. Several minutes later, the potential reached a steady state of about $15 \mathrm{mV}$ depolarization. However, in all the preparations examined $(n=12)$, a generation of action potentials could not be seen during the depolarization by the $20 \mathrm{mM} \mathrm{K}$ solution. When $\mathrm{NA}$ was applied to the tissue at the steady state, a depolarization of the smooth muscle membrane occurred, and in some of the preparations the depolarization was associated with action potentials. In Fig. 2a, the effects of electrical conditioning polarization on the NA-

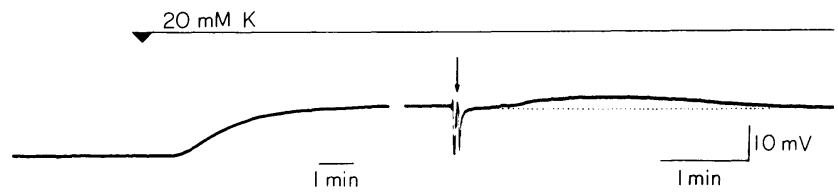

Fig. 1. The effects of the $20 \mathrm{mM} \mathrm{K}$ solution on the membrane potential of smooth muscle of the guinea-pig vas deferens recorded using the double sucrose-gap method. At the point marked by the triangle, the control solution was replaced with the $20 \mathrm{mM} \mathrm{K}$ solution. The electrical change by changing the solution comprises the changes in the membrane potential and liquid junction potential. At the arrow, NA was applied for a short period at a concentration of $10^{-5} \mathrm{M}$. 
a

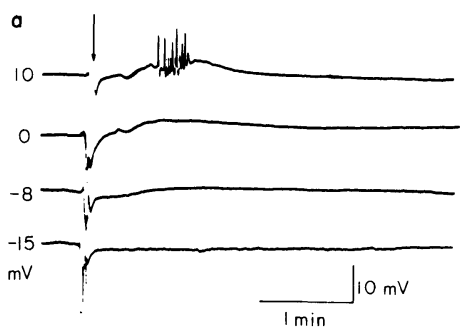

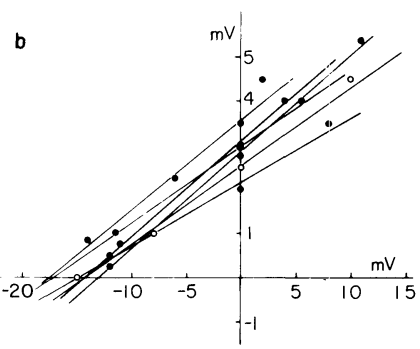

Fig. 2. The effects of electrical conditioning polarization on the NA-induced depolarization in the $20 \mathrm{mM} \mathrm{K}$ solution. (a), tracings obtained from the same preparation at the magnitude of conditioning polarization shown beside each tracing. Positive value, the value of the depolarization and negative one, the hyperpolarization. NA $\left(10^{-5} \mathrm{M}\right)$ was applied at the arrow in each tracing. (b), the relationship between the magnitude of the NA $\left(10^{-5} \mathrm{M}\right)$-induced response (ordinate) and the membrane potential (abscissa), shown taking the intact membrane potential in the $20 \mathrm{mM} \mathrm{K}$ solution as zero $\mathrm{mV}$. Results from six preparations are shown. Open circles from the preparation in (a).

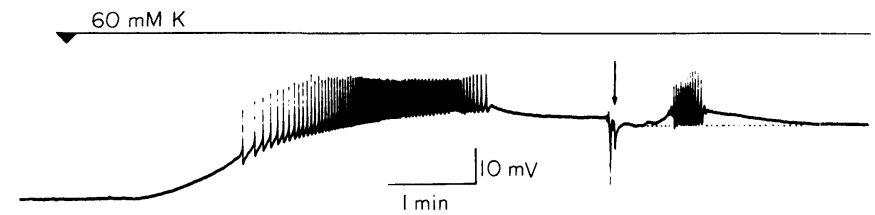

Fig. 3. The effects of the $60 \mathrm{mM} \mathrm{K}$ solution on the membrane potential of the smooth muscle of guinea-pig vas deferens. At the point marked by the triangle, the $60 \mathrm{mM} \mathrm{K}$ solution was employed. $\mathrm{NA}\left(10^{-5} \mathrm{M}\right)$ was applied at the arrow.

induced depolarization in the $20 \mathrm{mM} \mathrm{K}$ solution are shown. As can be seen, the magnitude of the NA-induced depolarization was enhanced by a conditioning depolarization and reduced by a conditioning hyperpolarization. When the magnitude of the NA-induced response was plotted against the membrane potential, taking the membrane potential in the $20 \mathrm{mM} \mathrm{K}$ solution without either the drug or conditioning polarization as zero $\mathrm{mV}$ (Fig. $2 \mathrm{~b}$ ), the points obtained from the same preparation were roughly on a straight line. The reversal potential in the $20 \mathrm{mM} \mathrm{K}$ solution ranged from 17.5 to $13.0 \mathrm{mV}(15.1 \pm 0.7 \mathrm{mV}, n=6)$ negative to the membrane potential of the smooth muscle cell.

In Fig. 3, the effects of the $60 \mathrm{mM} \mathrm{K}$ solution on the membrane potential are shown. By changing the solution, the potential shifted toward depolarizing direction. In all the preparations examined $(n=11)$, the potential change by the $60 \mathrm{mM} \mathrm{K}$ solution was associated with a transient generation of action potentials mostly at the initial phase. The membrane potential then reached a steady state of about $28 \mathrm{mV}$ depolarization, after spontaneous disappearance of action potentials. NA applied to the tissue at the steady state induced a depolarization of the smooth muscle membrane. The NA-induced depolarization, when it was 


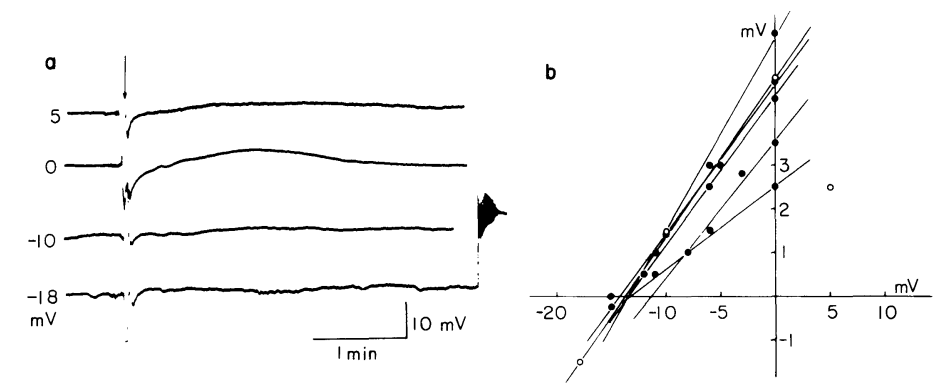

Fig. 4. The effects of electrical conditioning polarization on the NA-induced depolarization in the $60 \mathrm{mM} \mathrm{K}$ solution. (a), tracings obtained from the same preparation at the magnitude of conditioning polarization shown beside each tracing. (b), the relationship between the magnitude of the $\mathrm{NA}\left(10^{-5} \mathrm{M}\right)$ induced response (ordinate) and the membrane potential (abscissa), shown taking the intact membrane potential in the $60 \mathrm{mM} \mathrm{K}$ solution as zero $\mathrm{mV}$. Results form six preparations are shown. Open circles from the preparation in (a).

obtained only within the first several minutes after the tissue reached the steady state, was very often accompanied by a reoccurrence of action potentials. As shown in Fig. 4a, the conditioning hyperpolarization reduced the magnitude of the $\mathrm{NA}$-induced depolarization in the $60 \mathrm{mM} \mathrm{K}$ solution, similarly to the findings shown in the control and $20 \mathrm{mM} \mathrm{K}$ solutions. On the other hand, the conditioning depolarization did not affect or rather reduced the NA-induced depolarization, in contrast to the findings shown in the control and $20 \mathrm{mM} \mathrm{K}$ solutions. The reversal potential in the $60 \mathrm{mM} \mathrm{K}$ solution, obtained only by the conditioning hyperpolarization, ranged from 14.1 to $11.4 \mathrm{mV}(13.2 \pm 0.4 \mathrm{mV}, n=6)$ negative to the membrane potential of the smooth muscle cell.

\section{Discussion}

From the studies using the microelectrode technique, the resting membrane potential of smooth muscle of the guinea-pig vas deferens is known to be around $-60 \mathrm{mV}(-57 \mathrm{mV}$, Burnstock and Holman $1961 ;-61.4 \mathrm{mV}$, Kuriyama 1964). It is also known that the equilibrium potentials of $\mathrm{Na}, \mathrm{Cl}$ and $\mathrm{K}$ ions of the smooth muscle in the solution of normal ionic composition, are $42,-23$ and $-88 \mathrm{mV}$, respectively, taking their intracellular concentrations as 28,57 and 158 $\mathrm{mM}$ (Casteels 1970). In addition, the equilibrium potential of $\mathrm{Ca}$ ions is more positive than that of $\mathrm{Na}$ ions. Therefore, our previous (Wakui and Inomata 1985) and a part of the present results, showing that in the control solution $(5.9 \mathrm{mM} \mathrm{K})$, the reversal potential of the NA-induced depolarization of the smooth muscle membrane was $19.5 \pm 1.1 \mathrm{mV}(n=7)$ negative to the resting membrane potential, suggest that the reversal potential is likely reflected mostly by the $\mathrm{K}$ equilibrium potential. On the other hand, in the 20 and $60 \mathrm{mM} \mathrm{K}$ solutions, the reversal potential of the NA-induced depolarization was $15.1 \pm 0.7 \mathrm{mV}(n=6)$ and $13.2 \pm$ 
$0.4 \mathrm{mV}(n=6)$ negative to the expected membrane potential of the smooth muscle at the steady state in each solution (Figs. 2 and 4). Under the sucrose-gap method, we can not know the real size of the change in the membrane potential due to changing the external $\mathrm{K}$ concentration, because such an alteration of the external ionic composition also gives a change in the liquid junction potential as well as a change in the membrane potential (Bennett and Burnstock 1966). However, it is easily understood that the higher external $\mathrm{K}$ concentration induces the larger depolarization of the membrane, taking account that the membrane potential also of the smooth muscle cell is constituted largely by the chemical gradient of $\mathrm{K}$ ions across the cell membrane (Casteels 1970). Therefore, the above findings indicate that an increase in the external $\mathrm{K}$ concentration made a shift of the reversal potential of the NA-induced depolarization toward the positive direction - the larger the increase in the $\mathrm{K}$ concentration, the larger the size of the shift. Meanwhile, in the $20 \mathrm{mM}$ and $60 \mathrm{mM} \mathrm{K}$ solutions, the calculated equilibrium potential of $\mathrm{K}$ ions is $-52 \mathrm{mV}$ and $-24 \mathrm{mV}$, respectively. In addition, the $\mathrm{Na}$ equilibrium potential also varied in the solutions with different $\mathrm{K}$ concentrations used in this study, $38 \mathrm{mV}$ in the $20 \mathrm{mM} \mathrm{K}$ solution and $29 \mathrm{mV}$ in the $60 \mathrm{mM}$ $\mathrm{K}$ solution. However, the equilibrium potentials of $\mathrm{Ca}$ and $\mathrm{Cl}$ ions should be unchanged throughout all of the experiments in this study since their concentrations were kept constant in all of the solutions. Accordingly, the variation of the reversal potential of the NA-induced depolarization in the given different solutions in this study is compatible in nature only with the change in the $\mathrm{K}$ equilibrium potential. This, by the aid of the finding that the membrane conductance was decreased during the NA-induced depolarization (Wakui and Inomata 1985), provides evidence that in the smooth muscle of guinea-pig vas deferens, NA induces a reduction in the $\mathrm{K}$ conductance of the membrane.

Then, it remains a question as to why in the $60 \mathrm{mM} \mathrm{K}$ solution, an electrical conditioning depolarization did not enhance the magnitude of the NA-induced depolarization of the smooth muscle membrane (Fig. 4). Though further investigations seem to be required to explain the above problem, one possible explanation is that by an employment of such a very large membrane depolarization preceding the NA application, some factor, which seems to be indispensable for the process of a reduction in the $\mathrm{K}$ conductance by $\mathrm{NA}$, may be inactivated. This speculation is based on the findings that for the generation of the NA-induced depolarization, not only an existence of $\mathrm{Ca}$ ions in the external solution (Magaribuchi et al. 1971; Wakui and Inomata 1984), but also a movement of the $\mathrm{Ca}$ ions into the cytoplasm (Wakui and Fukushi 1986) are essential. A large membrane depolarization may reduce the amount of the influx of $\mathrm{Ca}$ ions by diminishing the electrical gradient across the membrane. 


\section{Acknowledgments}

We are grateful to Professor A. Nishiyama for his constant and enthusiastic interest in this study and for much helpful discussion of the results.

\section{References}

1) Anderson, N.C. (1969) Voltage-clamp studies on uterine smooth muscle. $J$. gen. Physiol., 54, 145-165.

2) Bennett, M.R. \& Burnstock, G. (1966) Application of the sucrose-gap method to determine the ionic basis of the membrane potential of smooth muscle. J. Physiol. (Lond.), 183, 637-648.

3) Bülbring, E. \& Szurszewski, J.H. (1974) The stimulant action of noradrenaline ( $\alpha$-action) on guinea-pig myometrium compared with that of acetylcholine. Proc. roy. Soc. Lond. B, 185, 225-262.

4) Bülbring, E. \& Tomita, T. (1969) Increase of membrane conductance by adrenaline in the smooth muscle of guinea-pig taenia coli. Proc. roy. Soc. Lond. B, 172, 89-102.

5) Bülbring, E., Ohashi, H. \& Tomita, T. (1981) Adrenergic mechanism. In : Smooth Muscle. Chapter 10, edited by E. Bülbring, A.F. Brading, A.W. Jones \& T. Tomita, Edward Arnold, London, pp. 219-248.

6) Burnstock, G. \& Holman, M.E. (1961) The transmission of excitation from autonomic nerve to smooth muscle cell. J. Physiol. (Lond.), 155, 115-133.

7) Casteels, R. (1970) The relation between the membrane potential and the ion distribution in smooth muscle cells. In: Smooth Muscle. Chapter 2, edited by E. Bülbring, A.F. Brading, A.W. Jones \& T. Tomita, Edward Arnold, London, pp. 70-99.

8) Kuriyama, H. (1964) Effect of calcium and magnesium on neuromuscular transmission in the hypogastric nerve-vas deferens preparation of the guinea-pig. J. Physiol. (Lond.), 175, 211-230.

9) Magaribuchi, T., Ito, Y. \& Kuriyama, H. (1971) Effects of catecholamines on the guinea-pig vas deferens in various ionic environments. Jap. J. Physiol., 21, 691-708.

10) Marshall, J.M. (1967) Comparative aspects of the pharmacology of smooth muscle. Fed. Proc., 26, 1104-1110.

11) Mekata, F. \& Niu, H. (1972) Biophysical effects of adrenaline on the smooth muscle of the rabbit common carotid artery. J. gen. Physiol., 59, 92-102.

12) Shuba, M.F. (1977) The mechanism of the excitatory action of catecholamines and histamine on the smooth muscle of guinea-pig ureter. J. Physiol. (Lond.), 264, 853864 .

13) Shuba, M.F., Gurkovskaya, A.V., Klevetz, M.J., Kochemasova, N.G. \& Taranenko, V.W. (1976) Mechanism of the excitatory and inhibitory actions of catecholamines on the membrane of smooth muscle cells. In: Physiology of Smooth Muscle, edited by E. Bülbring \& M.F. Shuba, Raven Press, New York, pp. 347-355.

14) Wakui, M. \& Fukushi, Y. (1986) Possible relationship between the release of calcium ions and inactivation of the potassium conductance induced by noradrenaline in smooth muscle of the guinea-pig vas deferens. Tohoku J. exp. Med., 150, 381-389.

15) Wakui, M. \& Inomata, H. (1984) Requirements of external $\mathrm{Ca}$ and $\mathrm{Na}$ for the electrical and mechanical responses to noradrenaline in the smooth muscle of guineapig vas deferens. Jap. J. Physiol., 34, 199-203.

16) Wakui,M. \& Inomata, H. (1985) Decrease in membrane conductance induced by noradrenaline in the smooth muscle of guinea-pig vas deferens. Pflügers Arch., 403, 109-111. 